\title{
Emotion and Explicit Verbal Memory: Evidence Using Malay Lexicon
}

\author{
Khairudin, R. ${ }^{1}$, Nasir, R. ${ }^{1}$, Halim, F. W. ${ }^{1}$, Zainah, A. Z. ${ }^{1}$, Wan Shahrazad, W. S. ${ }^{1}$, Ismail, K. ${ }^{1}$ \& Valipour, G. M. ${ }^{1}$ \\ 1 School of Psychology and Human Development, Faculty of Social Sciences and Humanities, Universiti \\ Kebangsaan Malaysia, Bangi, Malaysia \\ Correspondence: Khairudin, R., School of Psychology and Human Development, Faculty of Social Sciences and \\ Humanities, Universiti Kebangsaan Malaysia, 43600 UKM Bangi, Selangor, Malaysia. Tel: 60-3-8921-5286. \\ E-mail: rozainee@ukm.my
}

Received: June 4, $2012 \quad$ Accepted: June 16, $2012 \quad$ Published: July 16, 2012

doi:10.5539/ass.v8n9p38

URL: http://dx.doi.org/10.5539/ass.v8n9p38

\begin{abstract}
The dichotomy of emotional system and cognitive system has been debated for centuries. As a result, there is still much to know about the effects of emotions on memory. In two experiments, emotion was manipulated to investigate its effect on recall and recognition of words. Experiment 1 used a recognition test and experiment 2 used a free recall test. Emotion was manipulated in word stimuli: positive words, negative words and neutral words (baseline condition). Malay words were used as the verbal stimuli. The valences of the words were taken from ANEW. Results revealed that memory was better on the recognition test than recall test. Emotion had a significant effect on memory performance where both positive and negative emotions improved memory when compared to the baseline condition. The implication is that Malay words elicit a different result on explicit memory when emotional content of the words was manipulated.
\end{abstract}

Keywords: emotion, explicit, memory, Malay lexicon, recognition, free recall

\section{Introduction}

Memory is considered as the outcome of several cognitive functions which refers to the ability to encode, retain, and retrieve information at different points in time (Yuspeh and Vanderploeg, 2000). It has been studied extensively due to its substantial inclusion in human intellectual functioning, processes of perception and reasoning. Some theorists believe that memory is not a unitary system but is fractioned into different components (Stracciari et al., 1994). For example, memory may be broadly differentiated into short-term store and long-term store (Neath et al., 2003). Other theorists (eg., Squire, 1987) view memory into categories like explicit memory and implicit memory. Explicit memory is memory that we intend to remember and often we are conscious about the particular prior experience. Implicit memory is memory that is not in our conscious awareness (Hunt and Ellis, 2004). It refers to the memory for a learning event without making specific reference to that event.

Direct tests of memory, such as recall and recognition tasks, are often used to measure explicit memory (Schacter, 1987). A free recall test requires an item to be recalled without cuing. In a recognition test, a stimulus is presented and a decision is made whether it is the target item or not. Recognition can be tested by eliciting either a "yes" or "no" response whereby each item is judged individually, or by a forced choice procedure whereby one item from an array must be selected as the target.

Emotion and cognition has always been viewed as separate (Pessoa, 2009). Only recently there are interests to claim that the two are interdependence. Nevertheless, the debate still holds whether emotion and rational thinking are related: rational means having a reason while emotion is the production of strong feelings. It is said that strong emotions may block us from listening to, or even accepting reason. The dichotomization also rests on the idea that emotion is related to unconscious processing and subcortical activity, while cognition is related to conscious processing and cortical involvement (Pessoa, 2008). Such conception has been challenged by the growing development of neuroscience. Damasio (2001), for instance, has demonstrated the importance of emotion in decision making through his studies with brain damaged patients. He even suggests that effective decision making not only is not hampered by emotion, it requires emotion. 
Consequently, interest in the interface between emotion and cognition is increasing. There have been studies that show the influence of emotion on cognition. Hofer (1994) has shown that from the moment a new born baby opens its eyes, emotion is already playing a role in shaping the infant's cognition. An early positive emotional bond with mothers may aid in the development of earliest mental representations. Research has also shown that early visual processing of stimuli is improved by signals of emotionality. That is, the positive or negative valence (relative to neutral) of a stimulus can change how we process that information. In a study by Sato et al. (2001), event related potentials (ERPs) were used to measure the brain activity of participants viewing emotional (happy or fearful) and neutral faces. Statistical analyses of the ERP data revealed that brain regions involved in early visual processing were more activated for emotional relative to neutral faces. If emotionality affects processes at an early visual processing stage, then emotionality may also affect higher order cognitive processes such as memory. Furthermore, Khairudin et al. (2011) found that there was an advantage for positive emotional contents on explicit memory than on negative contents. These studies highlighted the impact of emotion on cognition.

Impetus in research has also extended to studies on the relationship between memory and emotion. Effects of emotional contents have been investigated on explicit memory and implicit memory separately by using different materials, such as emotional words (e.g., Mathews and Barch, 2006), pictures (e.g., Kensinger et al., 2007), and stories (e.g., Frank and Tomaz, 2000). Dillon et al. (2007) manipulated emotion regulation strategies and examine their effects on explicit memory and implicit memory. They found a dissociable effect of emotion regulation on these two types of memory: reappraisal of personal relevance of pictures improved explicit memory but suppressing emotion seemed to impair memory. There was no effect on implicit memory.

Studies on the impact of emotion on memory have been done using words. For example, Zachary and James (2008) have shown that negative emotional words elicit slower lexical decisions and naming than positive words. Kensinger and Corkin (2003) investigated memory performance on emotional words. They found that there was an advantage on memory for emotional words when compared to neutral words. Although studies have been done to investigate the impact of emotion on verbal memory (words), these studies were mainly done in the west where words or lexicon used were English. Very little, if not none, similar studies have been done using Malay lexicon. Will the same effect be generated using different lexicon, particularly Malay?

The current study is significant as it contributes into the better understanding of the effect of emotional contents on explicit memory. The results of the current study may further clarify the effects of emotional contents on explicit memory particularly by using verbal materials. In the current study, Malay words were used as stimuli in which their emotional content was manipulated. Most studies on effects of emotion on explicit memory have been on negative states. Bush and Geer (2001) stated that their study did have weaknesses, by not using positive emotional words. Accordingly, the current study attempted to provide evidence on the effects of different types of emotion (positive and negative) by directly comparing different types of emotion on explicit memory.

The main aim of the current study is to investigate the effects of different types of emotion (positive, negative, neutral (baseline)) explicit memory. The current study examined that whether negative and positive emotions can impact participants' abilities to remember words. In particular, participants studied a series of words, one third with a negative arousing, one third with positive arousing and the rest being neutral. At retrieval, participants were presented with a series of words, in which some of them were identical to those that participants had studied and some were new. Participants also had to freely recall words that they have learned.

\section{Method}

\section{Experiments 1 and 2}

Experiments were designed to study the effects of emotional contents on explicit memory. A mixed-factorial design was used: 1 between-subject factor: 2 task type (recall and recognition) and 1 within-subject factor: 3 valences (negative, positive and neutral (baseline)). In experiment 1 , free recall was used as the memory measure while in experiment 2, memory performance was measure by recognition.

\subsection{Participants}

The participants were fifty eight young adults (40 females: 18 males, ages $19-29, \mathrm{M}=22.56, \mathrm{SD}=2.54$; mean education $=15.77$ years, $\mathrm{SD}=1.42$ ), comprised of Universiti Kebangsaan Malaysia (National University of Malaysia) undergraduates and postgraduates students who were given course credit for their participation. Participants were randomly assigned to one of the two between-subjects' conditions (experiment 1 or experiment 2). So there were 29 participants in experiment 1 and the rest were in experiment 2. 


\subsection{Materials}

Word stimuli were selected from the Affective Norms for English Words (ANEW) (Bradley and Lang, 1999) for which normative valence and arousal scores were obtained via responses to the Self-Assessment Manikin (Bradley and Lang, 1994). From the ANEW pool, 60 words were selected, these words were then translated and back-translated by native speakers (Malaysian) using Brislin et al. (1973) back translation technique. Of the total 60 words, there were 20 positive and arousing words (mean valence $=7.90$; mean arousal $=6.35$ ), 20 negative and arousing words (mean valence $=2.26$; mean arousal $=6.66$ ), and 20 neutral and non-arousing words (mean valence $=5.03$; mean arousal $=3.74$ ) were selected. Negative words were selected to be low in valence and high in arousal, positive words were selected to be high in valence and in arousal and neutral words were selected to be not high or low in valence and not to be aroused (Table 1).

Table 1. Valence and arousal ratings for word stimuli used in experiment 1 and experiment 2

\begin{tabular}{llll}
\hline Group & $\begin{array}{l}\text { Positive } \\
(\text { Mean})\end{array}$ & $\begin{array}{l}\text { Negative } \\
\text { (Mean) }\end{array}$ & $\begin{array}{l}\text { Neutral } \\
\text { (Mean) }\end{array}$ \\
\hline Valence & 7.90 & 2.26 & 5.03 \\
Arousal & 6.35 & 6.66 & 3.47 \\
\hline
\end{tabular}

Source: Bradley \& Lang 1999

Table 1 shows the valence and arousal means for positive emotion, negative emotion and neutral conditions for word stimuli.

\subsection{Experimental Procedure}

The experimental session consisted of three phases: study, break and test phase. The duration of each study phase, followed by a 30 minute rest interval before the test phase. There was a practice session before each of study and test phases to make sure that each participant understood the nature of the task.

Participants were instructed that they were taking part in a study of how people assess different types of words. They were told that the task they had to do with the words they were going to see on the screen was to assess their pleasantness from 1 (very unpleasant) to 7 (very pleasant). They were encouraged to respond quickly, basing their answers on their first impression. They were not informed of any subsequent memory test.

The experiment was administered individually to participants. Stimuli were presented on a laptop using PsychoPy, experimental control software developed by Peirce (2007). Participants were seated comfortably and presented with the same words. They received their instructions via computer.

\subsection{Study Phase}

Practice phase was conducted to familiarize the participants with the experimental procedure; the practice phase consisted of 6 words. These words were presented to ensure that participants understood the procedures. Once the practice phase had been successfully completed, the study phase began. In the study phase of the experiment, the participants saw a list of 30 words (10 positive emotional, 10 negative emotional, and 10 neutral words). The instruction was written on the computer screen as well as verbally communicated to the participant. Participants were asked to assess their pleasantness from 1 (very unpleasant) to 7 (very pleasant).

\subsection{Test Phase}

Following the study phase, there was a delay (break) of 30 minutes. After break time the practice phase were preformed to help participants understand the test procedure. The instruction was written on the computer screen as well as verbally communicated to the participant. Following the practice phase and after making sure that participants understood the procedure the test phase was performed.

\subsubsection{Experiment 1: Recognition Test}

During the test phase of the experiment, participants view random list of 60 words, half were new words (10 positive, 10 negative, and 10 neutral) and the rest were the studied words (10 positive, 10 negative, and 10 neutral), using the same equipment as in the study task. New and studied words were randomized in order to make sure that no more than three words of the same valence were presented consecutively.

Subjects were required to click "yes" on the computer screen if they judged that the word had been previously studied in the study phase, and click "no" if they did not judge that the word had been presented in the study phase or simply to choose "yes" response for the previously studied words and a "no" answer for the new words. 
They were asked to judge as accurately as possible. Words were presented until a response was registered, then the next word was presented, so the total time taken to complete the recognition task varied for each participant.

\subsubsection{Experiment 2: Free Recall Test}

Immediately after the filler task, participants were instructed to write on a sheet of paper all the words they could remember from those that had appeared on the computer, regardless of their appearance order. They were given enough time to complete this task.

\section{Results}

Correct responses were collected from the different conditions of the experimental design. D-prime analysis (d') was done on the data to account for response bias:

$$
\begin{aligned}
& d^{\prime}=z(H)-z(F) \\
& d^{\prime}=d \text {-prime } \\
& H=\text { Hit rate } \\
& F=\text { False alarm } \\
& z(H)=\sqrt{ } 2(2 H-1) \\
& z(F)=\sqrt{ } 2(2 F-1)
\end{aligned}
$$

\begin{tabular}{|c|c|c|c|}
\hline & $\mathrm{t}$ & $\mathrm{df}$ & p-value \\
\hline Positive-Negative & 0.000 & 28 & 1.000 \\
\hline Positive-Neutral & 3.994 & 28 & $0.000 * *$ \\
\hline Negative-Neutral & 3.546 & 28 & $0.001 *$ \\
\hline
\end{tabular}

A two-way ANOVA was conducted on the d' values (i.e., corrected response: hit rate - false alarm). The factors involved were test type (recognition, free recall) as between-subject factor and emotions (positive, negative, neutral (baseline) as within-subject factor (Table 2).

Table 2. T-test results of paired comparison for the experimental conditions

Table 2 shows the summary of t-test results for different emotions (positive, negative, and neutral (baseline)) on recognition memory test (Experiment 1)

Results from the ANOVA showed that valence factor reached significance $(\mathrm{F}(2,112)=10.352, \mathrm{p}<0.001)$. Test type also had a significant effect on the memory performance $(\mathrm{F}(1,56)=85.634, \mathrm{p}<0.001)$. Memory performance was better on recognition test than on free recall test. However, there was no interaction between the two factors $(\mathrm{F}(2,112)=1.189, \mathrm{p}<0.308)$. (see Table 3 and Figure 1$)$.

Table 3. Summary of ANOVA results

\begin{tabular}{cccc}
\hline & $\mathrm{F}$ & $\mathrm{df}$ & $\mathrm{p}$-value \\
\hline Emotion & 10.352 & 2 & $0.000^{*}$ \\
Test Type & 85.634 & 1 & $0.000^{*}$ \\
Emotion * Test Type & 1.189 & 2 & 0.308 \\
\hline
\end{tabular}

$* \mathrm{p}<0.05$

Table 3 presents the ANOVA results for emotion and test types. 


\section{Estimated Marginal Means of MEASURE_1}

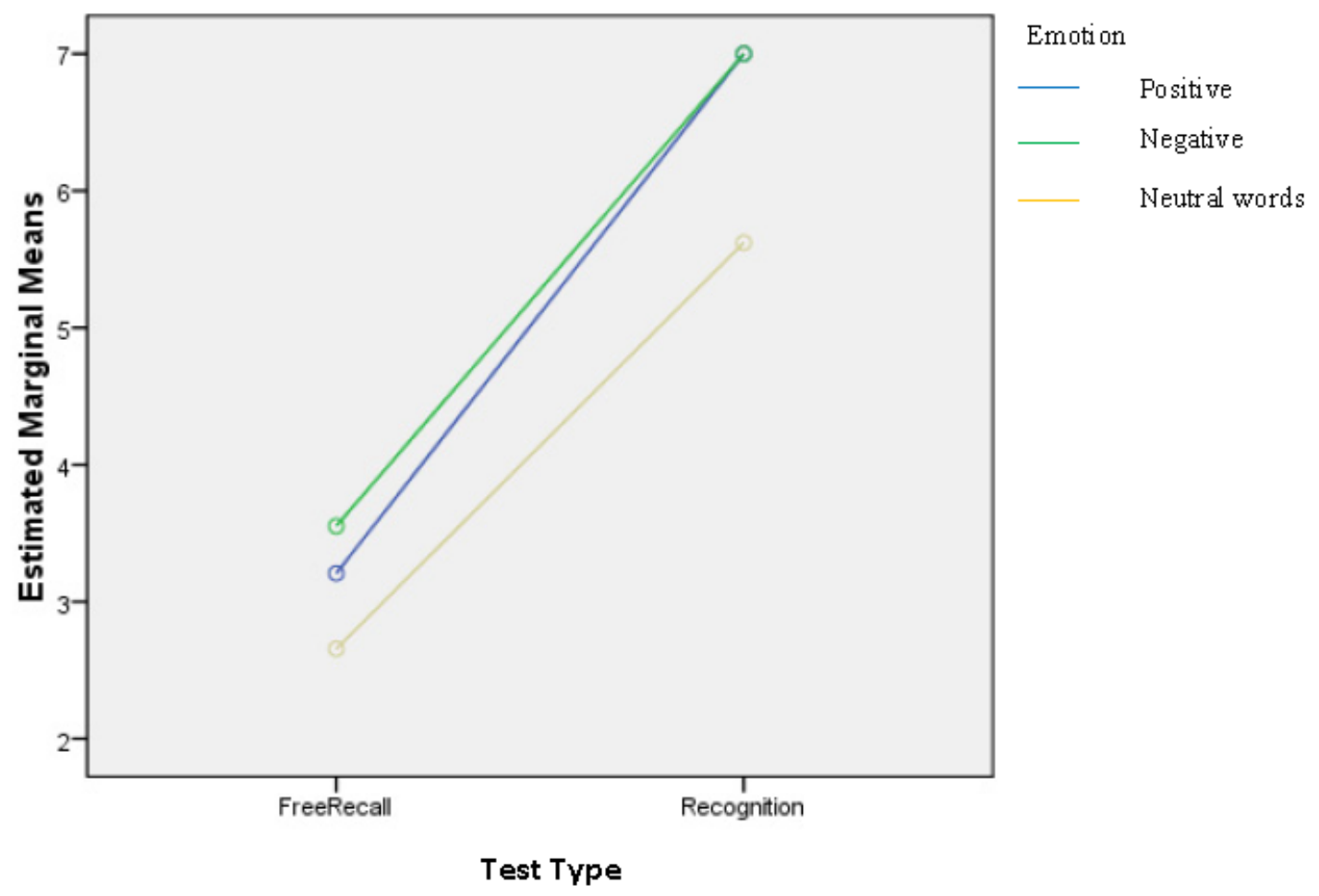

Figure 1. The mean d' values for each emotion as a function of test types

A separate analysis was done on the two test types (recognition, free recall) to examine the direction of valence effect. Paired sample t-tests on recognition test (experiment 1) showed that the significant differences were between positive words and neutral words $(\mathrm{t}(28)=3.994, \mathrm{p}<0.001)$; and negative words and neutral words $(\mathrm{t}(28)$ $=3.546, \mathrm{p}<0.01)$. There was no difference between positive and negative words on memory performance $(\mathrm{t}(28)$ $=0.00, \mathrm{p}=1)($ Table 3$)$.

Paired sample t-tests on free recall tests (experiment 2) revealed that the significant difference was between negative and neutral words. The difference was only marginally significant $(\mathrm{t}(28)=2.081, \mathrm{p}=0.04)$. Memory performance was not any different between positive and neutral words $(\mathrm{t}(28)=1.505, \mathrm{p}=0.144)$. Also, there was no difference in memory performance between positive and negative words $(t(28)=1.000, p=0.326)$ (Table 4).

Table 4. T-test results of paired comparison for the experimental conditions

\begin{tabular}{cccc}
\hline & $\mathrm{t}$ & $\mathrm{df}$ & $\mathrm{p}$-value \\
\hline Positive-Negative & -1.000 & 28 & 0.326 \\
Positive-Neutral & 1.505 & 28 & 0.144 \\
& & & \\
Negative-Neutral & 2.081 & 28 & $0.047^{*}$ \\
\hline
\end{tabular}

${ }^{*} \mathrm{p}<0.05$

Table 4 shows the summary of the t-test results for different emotions (Positive, Negative, and Neutral (Baseline)) on free recall test (Experiment 2) 


\section{Discussion}

The results from the current study showed that there was a significant effect of emotional content in word stimuli on explicit memory performance. Specifically, positive words were better remembered than neutral words. Negative words were also better remembered than neutral words. These were particularly obvious on the recognition test (experiment 1). When the test was a free recall (experiment 2), only negative words had an advantage over neutral words on memory performance. There was no difference on memory between positive and negative words. What can be deduced from these results is that emotional words indeed had an effect on memory regardless whether the valence was positive or negative. It was an advantageous effect where valence improved memory, in this case explicit memory. The present results are somewhat inconsistent with some of the previous studies which have found an advantage of positive emotion over negative ones (D'Argembeau et al., 2005; White, 2002; Jay et al., 2008). Here, we found that both positive and negative words increased memory. One explanation for the positive word effect is that positive words induce orienting responses in people (Khairudin et al., in press). This is because people's neutral or normal state tends to be more toward the positive stimuli. The superior performance for positive emotions can be accounted by the fact that positive emotions trigger the active application of knowledge structures to cognitive processes, which supports successful performance (e.g. Ashby et al., 1999; Fiedler, 1991). The advantage of negative words on explicit memory performance may be explained by the evolutionary framework. According to Kensinger et al. (2007), people tend to focus on threatening information for survival reasons. Attention on threatening or negative information could save lives by guiding actions and planning future events.

It is noteworthy to point out that the words used in the current study were from the Malay lexicon. With Malay words we have found that both positive and negative words had an advantage on memory performance. This is different from those results found with English words (e.g., Fossati et al., 2003) where positive words were better remembered than negative ones. Another thing to take note is that these effects were found on explicit memory tests. Different results were acquired when emotional content was examined on implicit memory. For example, Khairudin et al. (in press) found a superior memory performance for positive words than negative ones. Here we have shown that when participants had to remember the emotional words explicitly, both positive and negative valences improved memory when compared to a baseline condition (neutral words). Based on these results, it can be suggested that when the verbal memory involved emotional Malay words, people could remember better when they had to recall them explicitly. It is possible that emotional Malay words were not discriminated by their different valences (positive or negative). Instead, emotion (regardless it being positive or negative), triggered explicit memory better than non-emotional stimuli (neutral words).

It was also found in the current study that memory performance was better on recognition test than free recall test. This is somewhat not surprising as people are generally better at recognizing things they have experienced than recalling those things from memory. This is because most recognition tasks provide cues for memory (Gillund and Shiffrin, 1984). The cues will subsequently facilitate memory search. On the contrary, recall test involves retrieving information from memory itself which requires thorough search through memory.

\section{Conclusion and Implication}

In conclusion, the current study has supported other studies on emotion that have shown the superiority effect of emotional content on memory. Nevertheless, the current results are new findings where improved memory performance was found with both positive and negative words. We have found different results due to the stimuli used (Malay words) and memory test which was an explicit memory test. The implication is that Malay lexicon elicits different results than other languages particularly English when recalled explicitly. This suggests that Malay being Asian, could be different culturally than the west. Unlike an English speaking culture, the Malays are sensitive for both positive and negative emotions. Memory for English words are not only different when the valences of the words differ (positive or negative), it is also sometimes suppressed by negative emotional content. Some caveats are in order. The current study did not examine cultural factor directly. We did not compare respondents with different cultural background. Therefore, the conclusion should be taken with caution. Nevertheless, the findings present new direction for explicit memory research particularly when emotional content in words were taken from the Malay lexicon.

\section{References}

Ashby, F. G., Isen, A. M., \& Turken, A. U. (1999). A neuropsychological theory of positive affect and its influence on cognition. Psychological Review, 106, 529-550. http://dx.doi.org/10.1037/0033-295X.106.3.529 
Bradley, M. M., \& Lang, P. J. (1994). Measuring emotion: The self-assessment manikin and the semantic differential. Journal of Behavior Therapy and Experimental Psychiatry. 25(1), 49-59. http://dx.doi.org/10.1016/0005-7916(94)90063-9.

Bradley, M. M., \& Lang, P. J. (1999). Affective norms for English words (ANEW): Stimuli, instruction manual and affective ratings. Technical report C-1, Gainesville, FL. The Center for Research in Psychophysiology, University of Florida.

Brislin, R. W., Lonner, W. J., \& Thorndike, R. M. (1973). Cross-cultural research methods. New York: John Wiley \& Sons.

Bush, S. I., \& Geer, J. H. (2001). Implicit and explicit memory of neutral, negative emotional and sexual information. Archives of Sexual Behavior, 30(6), 615-631. http://dx.doi.org/10.1023/A: 1011915001416

D'Argembeau, A., Comblain, C., \& van der Linden, M. (2005). Affective valence and the self reference effect: Influence of retrieval conditions. British Journal of Psychology, 96, 457-466. http://dx.doi.org/10.1348/000712605X53218

Damasio, A. R. (2001). Emotion and the human brain. Annals of the New York Academy of Sciences. Wiley Online Library.

Dillion, D. G., Ritchey, M, Johnson B. D., \& LaBar, K. S. (2007). Dissociable effects of conscious emotion regulation strategies on explicit and implicit memory. Emotion, 7(2), 354-365. http://dx.doi.org/10.1037/1528-3542.7.2.354

Fiedler, K. (1991). On the task, the measures, and the mood in research on affect and social cognition. In J. P. Forgas (Ed.), Emotion and social judgments: An introductory review (pp. 83-104). London: Routledge.

Fossati, P., Hevenor, S. J., Graham, S. J., Grady, C., Keightley, M. L., Craik, F., \& Mayberg, H. (2003). In search of the emotional self: An fMRI study using positive and negative emotional words. The American Journal of Psychiatry, 160(11), 1938-1945. http://dx.doi.org/10.1176/appi.ajp.160.11.1938

Frank, J. E., \& Tomaz, C. (2000). Enhancement of declarative memory associated with emotional content in a Brazilian sample. Brazilian Journal of Medical Biological Research, 33(12), 1483-1489. http://dx.doi.org/10.1590/S0100-879X2000001200013

Gillund, G., \& Shiffrin, R. M. (1984). A retrieval model for both recognition and recall. Psychological Review, 91(1), 1-67. http://dx.doi.org/10.1037/0033-295X.91.1.1

Hofer, M. A. (1994). Early relationships as regulators of infant physiology and behavior. Acta Paediatric, 83(s397), 9-18. http://dx.doi.org/10.1111/j.1651-2227.1994.tb13260.x

Hunt, R. R., \& Ellis, H. C. (2004). Fundamentals of cognitive psychology. (7th ed.). New York: McGraw-Hill.

Jay, T., Caldwell-Harris, C., \& King, K. (2008). Recalling taboo and non-taboo words. American Journal of Psychology, 121(I), 83-103. http://dx.doi.org/10.1111/j.1745-6924.2009.01115.x

Kensinger, E. A., \& Corkin, S. (2003). Memory enhancement for emotional words: Are emotional words more vividly remembered than neutral words? Memory \& Cognition, 31(8), 1169-1180. http://dx.doi.org/10.3758/BF03195800

Kensinger, E. A., Garoff-Eaton, R. J., \& Schacter, D. L. (2007). How negative emotion enhances the visual specificity of a memory. Journal of Cognitive Neuroscience, 19, 1872-1887. http://dx.doi.org/10.1162/jocn.2007.19.11.1872.

Khairudin, R., Valipour, G. M, Nasir, R., \& A. Z. Zainah. (in press). Emotions as intermediaries for implicit memory retrieval processing: Evidence using word and picture stimuli. Asian Social Science.

Khairudin, R., Valipour, G. M., Wan Shahrazad, W. S., Nasir, R., \& Halim F. W. (2011). Effects of emotional contents on explicit memory process. Pertanika Journal of Social Sciences \& Humanities, 19(S), 17-26.

Mathews, J. R., \& Barch, D. M. (2006). Episodic memory for emotional and non-emotional words in individuals with anhedonia. Psychiatry Research, 143(2-3), 121-133. http://dx.doi.org/10.1016/j.psychres.2005.07.030

Neath, I., Farley, L. A., \& Surprenant, A. M. (2003). Directly assessing the relationship between irrelevant speech and articulatory suppression. The Quarterly Journal of Experimental Psychology Section A: Human Experimental Psychology, 56(8), 1269-1278. http://dx.doi.org/10.1080/02724980244000756

Peirce, J. W. (2007). PsychoPy - Psychophysics software in Python. Journal of Neuroscience Methods, 162(1-2), 8-13. http://dx.doi.org/10.1016/j.jneumeth.2006.11.017 
Pessoa, L. (2008). On the relationship between emotion and cognition. Nat Rev Neuroscience, 9(2), 148-158. http://dx.doi.org/10.1038/nrn2317

Pessoa, L. (2009). Cognition and emotion. Scholarpedia, 4(1), 4567. http://dx.doi.org/10.4249/scholarpedia.4567

Sato, W., Kochiyama, T., Yoshikawa, S., \& Matsumura, M. (2001). Emotional expression boosts early visual processing of the face: ERP recording and its decomposition by independent component analysis. Cognitive Neuroscience and Neuropsychology, 12(4), 709-714.

Schacter, D. L. (1987). Implicit memory: History and current status. Journal of Experimental Psychology: Learning. Memory and Cognition, 13(3), 501-518. http://dx.doi.org/10.1037/0278-7393.13.3.501

Squire, L. R. (1987). Memory and brain. New York: Oxford University Press.

Stracciari, A., Ghidoni, E., Guarino, M., Poletti, M., \& Pazzaglia. (1994). Post-traumatic retrograde amnesia with selective impairment of autobiographical memory. Cortex: A Journal Devoted to the Study of the Nervous System and Behavior, 30(3), 459-468.

White, R. T. (2002). Memory for events after twenty years. Applied Cognitive Psychology, 16, 603-612. http://dx.doi.org/10.1002/acp.819

Yuspeh, R. L., \& Vanderploeg, R. D. (2000). Spot-the-word: A measure for estimating premorbid intellectual

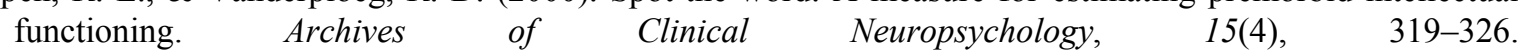
http://dx.doi.org/10.1093/arclin/15.4.319

Zachary, E., \& James S. A. (2008) Automatic vigilance for negative words is categorical and general. Emotion, 8(4), 453-457. http://dx.doi.org/10.1037/a0012887 